\title{
He-Polymer Microchip Plasma (PMP) System Incorporating a Gas-Liquid Separator for the Determination of Chlorine Levels in a Sanitizer Liquid
}

\author{
Joosuck Oh, Y. H. Kim, and H. B. Lim \\ Department of Chemistry, Dankook Lniversity, XSBT, Iongin, Gleonggi 4+8-701, Korea \\ E-mail: plasmaia damkook ackr: hblimiádkuedu \\ Received October 10, 2008, Accepted Jamary 12, 2009
}

\begin{abstract}
The authors describe an analytical method to deternine total chlorine in a sanitizer liquid, incorporating a lab-made He-rf-plasma within a PDMS polymer microchip. Helium was used instead of Ar to produce a plasma to achieve efficient $\mathrm{Cl}$ excitation. A quartz tube $\mathrm{I}$ nun i.d. was embedded in the central channel of the polymer microchip to protect it from damage. Rotational temperature of the He-microchip plasma was in the range $1350-3600 \mathrm{~K}$, as estimated from the spectrum of the $\mathrm{OH}$ radical. Chlorine was generated in a volatilization reaction vessel containing potassium permanganate in combination of sulfuric acid and then introduced into the polymer microchip plasma (PMP). Atomic emission lines of $\mathrm{Cl}$ at $438.2 \mathrm{~nm}$ and $837.7 \mathrm{~nm}$ were used for analy sis; no emission was observed for Ar plasma. The achieved limit of detection was $0.81 \mathrm{ug} \mathrm{mL} \mathrm{m}^{-1}$ (If powers of $30-70 \mathrm{~W}$ ), which was sensitive enough to analyze sanitizers that typically contained $100-200 \mu \mathrm{g} \mathrm{mL}$ of free chlorine in chlorinated water. This study demonstrates the usefulness of the devised PMP system in the food sciences and related industries.
\end{abstract}

Key Wonds: He plasma. Atomic emission. Determination of chlorine. Polỵmer microchip plasma

\section{Introduction}

Chlorinated water is used as a sanitizer for sterilizing various types of vegetables and foods. typically at concentrations of $100-200 \mu \mathrm{g} / \mathrm{mL}^{1-3}$ Since chlorine content directly influences sanitization efficiency the determination of total chlorine provides useful control information. Unfortunately. the range of analytical methods available for this purpose is severely limited in terms of their practical applications. For example. ion chromatography (IC) is too sensitive and expensive to be used in the manufacturing line to detect such a high concentration. Plasma based methods, such as inductively coupled plasma atomic emission spectrometry (ICPAES). can efficiently and selectively atomize chlorine and facilitate its analysis spectroscopically ${ }^{4 \cdot 6}$ but considerable energy is required to excite and ionize chlorine. Moreover. plasma based methods devised to date are expensive and do not meet the requirements of industrial users despite their sensitivities and reliabilities. and thus. smaller and more cost effective systems are required for production use. Various types of micro plasmas have been recently described. such as. $\mathrm{CCP}^{7: 9} \mathrm{MIP}^{+1,16,11} \mathrm{ICP}^{12,13}$ and others. which can detect halogens. However. argon plasmas have insufficient energy to excite halogens. ${ }^{14}$ and thus. helium has been used instead due to the higher excitation and ionization energy. The thermal properties of plasmas can be estimated using several techniques, such as, mass spectrometry. Langmuir probe, and optical techniques. ${ }^{9.15-18}$ Furthermore, rotational temperatures of plasmas can be estimated from rotational temperatures from $\mathrm{OH}$ radical emission spectra and Boltzmann plotting. ${ }^{19}$

Even though the He plasma operates at ligh temperatures. water vapor entering the plasma with the cllorine can be problematic. Therefore. in the devised system. chlorine is dried before being introduced to the plasma. Various techniques are available to remove water vapor for the analysis of metals. for example. hydride generation and cold vapor generation. ${ }^{2(1)}$ Recently. a method of generating gaseous halogens from halides by oxidation was reported for a He-microchip plasma-based method. ${ }^{4}$

Our laboratory has previously described Ar polymer microchip plasma (PMP) systems. ${ }^{2]}$ In the present study. a He-PMP sy'stem with a gas-liquid separator and a reaction cell was built for the determination of chlorine in sanitizer solutions. with a view toward its usage for manufacturing process control in the food industry. The temperature of He plasmas was estimated by determining $\mathrm{OH}$ rotational temperatures and compared to those generated by Ar plasmas. Chlorine vapor was generated and dried in a gas-liquid separator that was composed of a reaction vessel and a condenser. then introduced into the He microchip plasma for excitation and spectroscopic analysis.

\section{Experimental}

Microchip plasma system. A lab-fabricated. PDMS microchip He-plasma with a high-resolution detection system was built. as shown in Fig. 1. The rf plasma was contained in a quartz tube ( $1 \mathrm{~mm}$ i.d. and $2 \mathrm{~mm}$ o.d.), which was embedded in the central channel ( $2 \mathrm{~nm}$ diameter. $50 \mathrm{~nm}$ long) of the PDMS polymer chip. as described in a recent article. ${ }^{2]}$ In order to achieve $\mathrm{Cl}$ excitation. helium was used instead of argon. and thus the quartz tube was required to resist the higher temperatures generated by the He plasma than $\mathrm{Ar}$ plasmas. ${ }^{22}$ Enitted light was collected using an optical fiber (protected by a He flow of $300 \mathrm{~mL} \mathrm{~min}$ ) embedded at the downstream end of the channel. and then dispersed by a monocluromator $(0.70 \mathrm{~m}$ focal length. Model DM-700M, Dongwoo Optron. Korea) equipped with a photomultiplier tube (Hantamatsu photonics. Model R955) and a dual grating (1200 grooves/ $/ \mathrm{mm}$ for a $750 \mathrm{~nm}$ blazed angle and 2400 groove 


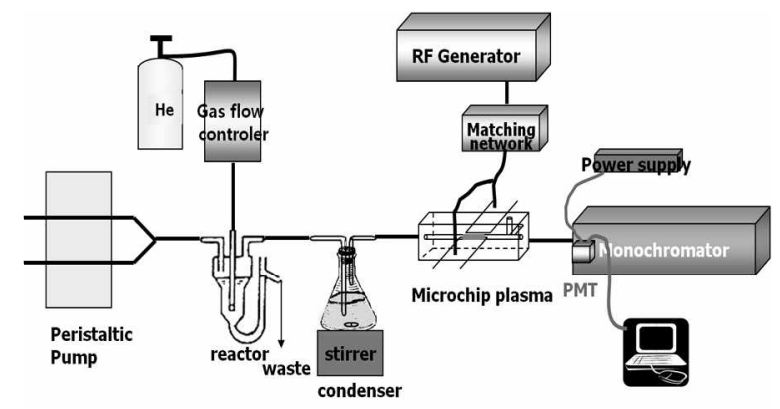

Figure 1. Schematic of the PDMS polymer He microchip plasma system with a gas-liquid separator.

Table 1. Optimized experimental conditions

\begin{tabular}{lc}
\hline He gas flow & About $0.5 \mathrm{~L} / \mathrm{min}$ \\
Uptake rate for sample solution and & $8 \mathrm{~mL} / \mathrm{min}$ \\
oxidizing reagent & $60 \mathrm{~W}$ \\
RF power & $750 \mathrm{~V}$ \\
PML voltage & $100 \mu \mathrm{m}$ \\
\hline Slit width & \\
\hline
\end{tabular}

for a 300nm blazed angle). Rf power was supplied at $15-70 \mathrm{~W}$ (13.56 MHz. Model PG-300A. Hwa Yong Tech., Korea) to the $\mathrm{Cu}$ electrodes to generate the plasma at a $\mathrm{He}$ gas flow of ca. $0.5 \mathrm{~L} \mathrm{minn}^{-1}$. which was controlled using a ball type flow meter.

Sample introduction and measurement. The reaction vessel. ${ }^{4}$ in which cllorine is generated was made of Pyre ${ }^{{ }^{-\underline{R}}}$ glass. as shown in Fig. 1. Samples were reacted with a mixture of 10 $\mathrm{mM} \mathrm{KMnO}_{4}$ (Sigma-Aldrich $99 \%+$ A.C.S. reagent) and $9 \mathrm{M}$ sulfuric acid (electronic grade. Dongwoo Finechem Co. Ltd). both were pumped into the reaction vessel using a peristaltic pump (Gilson. Miniplus 3). The chlorine gas so generated was passed in a He stream thru a glass frit of the reaction vessel. The chlorine gas was separated from the water vapor in the vessel and then dried in the condenser filled with concentrated sulfuric acid, and finally swept into the PMP by the helium nebulizer gas. $\mathrm{KCl}$ (first grade. Duksan Pharmaceutical $\mathrm{Co}$.. Ltd.) was dissolved in de-ionized water (18.2 M $\Omega$, prepared by Milli-Q. Millipore) and used as a reference solution. The $\mathrm{Cl}$ emission lines used for analysis were at $438.2 \mathrm{~nm}$ and $837.7 \mathrm{~nm}$

The optimized experimental conditions used are summarized in Table 1. Because the oxidation reaction is rapid. the $\mathrm{Cl}$ peak rose from the baseline within a few seconds of adding a sample

\section{Results and Discussion}

Rotational temperatures of $\mathrm{OH}$ mdial in the He-polymer micmehip plasma (PMP). Rotational temperature of plasmas was estimated using Boltzmann plots and the $\mathrm{Q}_{1}$ branch from $\mathrm{Q}_{1}(2)$ to $\mathrm{Q}_{1}(14)$ in the $3075-3115 \AA$ region of the $\mathrm{OH}$ radical. Figure 2 shows $\mathrm{OH}$ spectrum generated by the He-plasma. In order to reduce spectral interference a high resolution monochromator was employed in this study

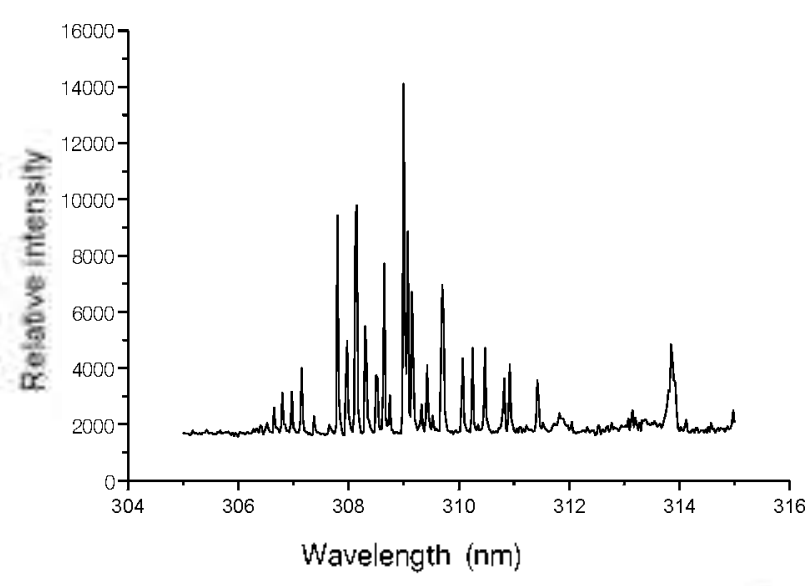

Figure 2. Emission spectrum of the $\mathrm{OH}$ molecule obtained from the He-PMP

The following equation (1) was used to generate Boltzmann plots:

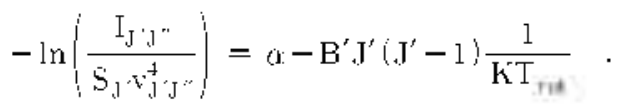

where, $B^{\prime}\left(J^{\prime}\right)$ is the rotational constant, $V_{J^{\prime} T^{\prime \prime}}$ is the frequency of the rotational line. $S_{\Gamma}$ is the emission line strength. $I_{J^{\prime}{ }^{\prime}}$ is the emission intensity of the (J'-J") transition. and $k$ is Boltzmann's constant. The line strength. $\mathrm{S}_{\mathrm{J}}$. can be obtained from equation (2) using a value of $24.97 \mathrm{~K}$ for $\mathrm{B} / \mathrm{k}$. which corresponds to the $2 \sum^{-}$state. ${ }^{18}$

$$
\mathrm{S}_{\mathrm{J}}=\frac{\left(2 \mathrm{~J}^{\prime}-1\right)}{4}
$$

The rotational temperature was obtained by plotting $-\ln \left(\mathrm{I}_{\mathrm{J} \cdot \mathrm{T}} / \mathrm{SJ}^{\circ} \mathrm{v}_{\left.\mathrm{J} \cdot \mathrm{J}^{*}\right)}\right)$ versus the corresponding $\mathrm{J}(\mathrm{J}+\mathrm{l})$ value of the emission band. As an example. a representative Boltzmann plot at an if power of $15 \mathrm{~W}$ is shown in Fig. 3. As shown by the plot. the rotational temperature was split into two ranges. i.e.. "high' and 'low', depending on $\mathrm{J}(\mathrm{J}+1)$ due to the nonequilibrium state of gas kinetic energy in the micro plasma. Measured tenperatures ranged from $1780 \mathrm{~K}$ to $3710 \mathrm{~K}$, which is both higher and narrower than that of the Ar plasma formed in a PDMS channel, i.e. 800-3200 K. For comparison purposes. the same operating conditions were used for the He-PMP and the Ar-PMP. although the He-PMP can operate at higher if powers. The 'high' tenperature was obtained at the lines of high excitation energy and showed relatively poor linear regression coefficient. $R$, because of its small emission intensity. This kind of a non-linear rotational distribution has been reported and discussed previously. ${ }^{9}$ and was found to correspond to the sum of two separate Boltzmann distributions.

Since the rotational temperature is dependent upon if power. we studied the effect of if power on this temperature; results are shown in Fig. 4. When if power was increased from 15 to $40 \mathrm{~W}$ for the He-PMP at the same operating condition as for the Ar-PMP for comparison. both the estimated 'high' and 'low' gas temperatures decreased from 3710 to $31+1 \mathrm{~K}$ and 


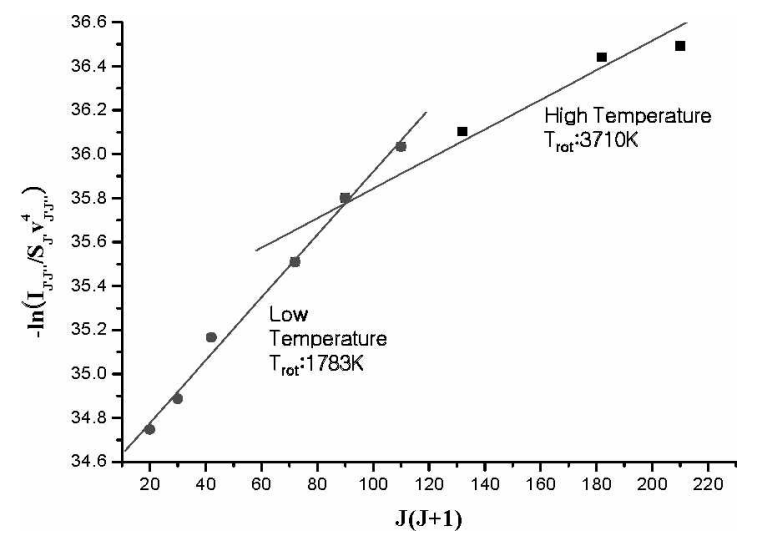

Figure 3. Boltzmann plot of the $\mathrm{OH}$ molecular band using the $\mathrm{He}-\mathrm{PMP}$ at $15 \mathrm{~W}$.

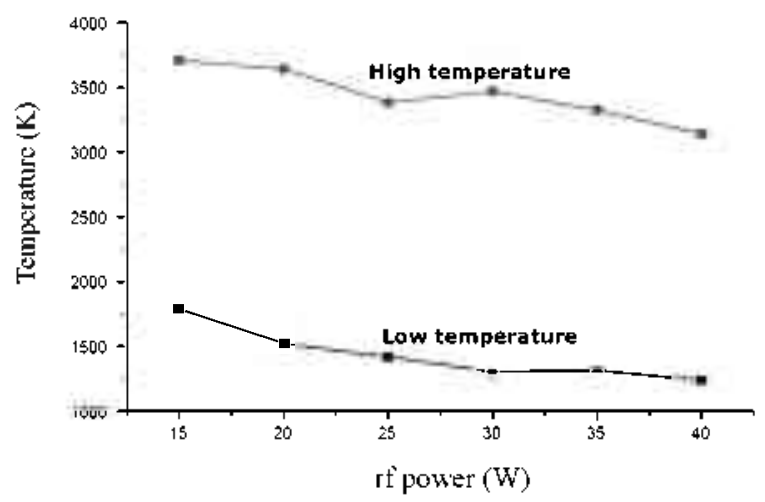

Figure 4. Relation between gas kinetic temperature and if power supplied to the He-PMP.

from 1780 to $1240 \mathrm{~K}$ respectively: Due to the higher temperature in the He-PMP, robustness to water loading and analytical performance for the detection of metal ions was expected to be improved. compared to the Ar plasma. In addition it should be noted that the He-PMP is capable of operating at powers substantially higher than $40 \mathrm{~W}$. and thus. it is likely to be more stable and robust than the Ar-PMP.

Measurement of $\mathrm{Cl}$ levels. As was expected the high ionization potential of $\mathrm{He}, 24.58 \mathrm{eV}$ improved the emission intensity of $\mathrm{Cl}(\mathrm{I})$ at $\mathrm{I} 2.96 \mathrm{eV}$. In fact. the $\mathrm{He}-\mathrm{PMP}$ produced $\mathrm{Cl}$ emission that was strong enough to be detected in the low power range (30-70 W). Furthermore, because the quartz tube was inserted into the central channel of the PDMS polymer microchip. the He-PMP system can be operated at higher powers. However the $30-70 \mathrm{~W}$ power range was adequate for our purposes for total chlorine levels of $-10,000 \mu \mathrm{g} / \mathrm{mL}$.

Although various $\mathrm{Cl}(\mathrm{I})$ emission lines were examined for analytical purposes. i.e.. $107.1 \mathrm{~nm} .134 .7 \mathrm{~nm} .+38.2 \mathrm{~nm} .479 .4$ num. $489.6 \mathrm{rm}$. and $837.7 \mathrm{rm}$. only at $438.2 \mathrm{~nm}$ and $837.7 \mathrm{~mm}$ were used because the sensitivities of the other lines were inadequate, as is listed on the website of the NIST (National Institute of Standards and Technology). ${ }^{23}$ For the He-PMP. $\mathrm{Cl}(\mathrm{I})$ emission under optimized conditions was strongest at $837.7 \mathrm{~nm}$, which concurred with NIST data. Although $\mathrm{Cl}(\mathrm{II})$ emission was expected to show strong intensity in the vacuum region, 107.1 $\mathrm{nm}$ and $134.7 \mathrm{~nm}$, no such emission was obser-

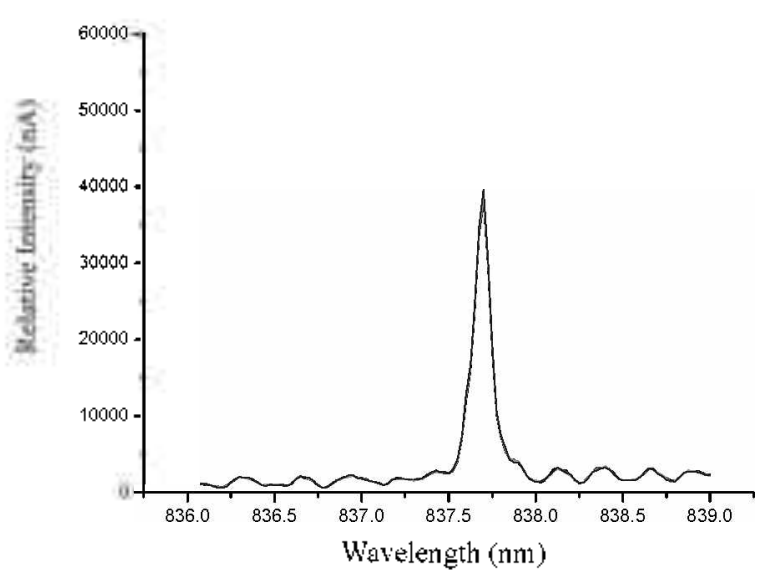

Figure 5. Spectrum of Cl(T) at $837.7 \mathrm{~nm}$ for $300 \mu \mathrm{g} / \mathrm{mL} \mathrm{KCl}$ using the He-PMP.

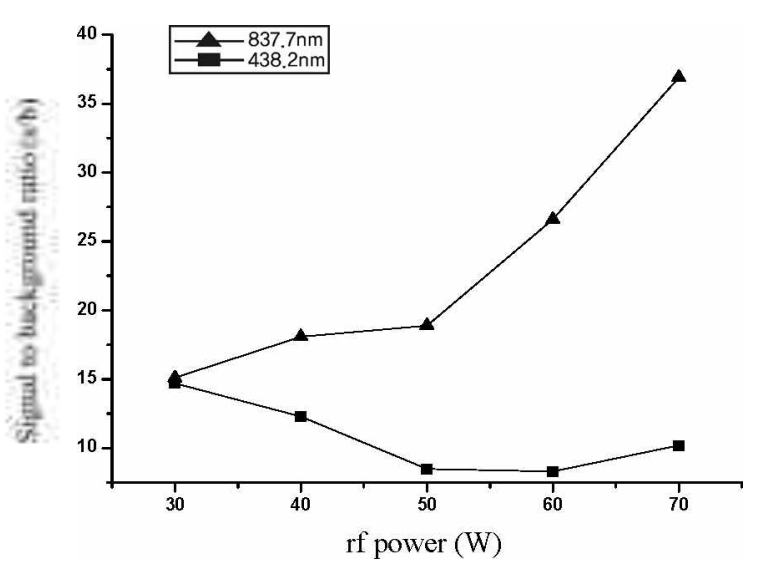

Figure 6. Changes in signal to background ratio (s/b) for $\mathrm{Cl}$ (I) lines for the He-PMP system.

ved for our He-PMP system.

The spectrum in the vicinity of the $837.7 \mathrm{~nm}$ line is shown in Fig. 5, for a $300 \mu \mathrm{g} / \mathrm{mL} \mathrm{KCl}$ control sample. The enission intensities of the peaks were integrated and background contributions were subtracted to obtain net enission intensities for four replicates. During the optimization process. signal to noise ratios were determined when if power was increased from 30 to $70 \mathrm{~W}$ : results are shown in Fig. 6. The two wavelengths of interest showed opposite characters in this respect. i.e., the signal to background ( $(\mathrm{s} / \mathrm{b})$ ratio of the $837.7 \mathrm{~nm}$ line increased. whereas that of the $438.2 \mathrm{~nm}$ decreased. Noticeably the $s / b$ ratio of the $438.2 \mathrm{~nm}$ became smaller than the $837.7 \mathrm{~nm}$ as the power increased. probably due to higher background level and higher transition energy' required. Although higher sensitivities can be achieved at higher powers, measurements were carried out at $70 \mathrm{~W}$ in this experiment due to the sensitivity required for sanitizer analy sis and the thermal stability of the PDMS microchip. Using the optimized conditions. the calibration curve of $\mathrm{Cl}(\mathrm{I})$ at 837.7 nm was as is shown in Fig. 7. The best attainable detection limit (using the $3 \sigma$ criterion) and using potassium permanganate as oxidant was found to be $0.81 \mu \mathrm{g} / \mathrm{mL}$. which was sensitive enough to analyze samples containing $\sim 100 \mu \mathrm{g} \mathrm{mL}^{-1}$ of chlorine in the form of chlorinated compounds in water. 


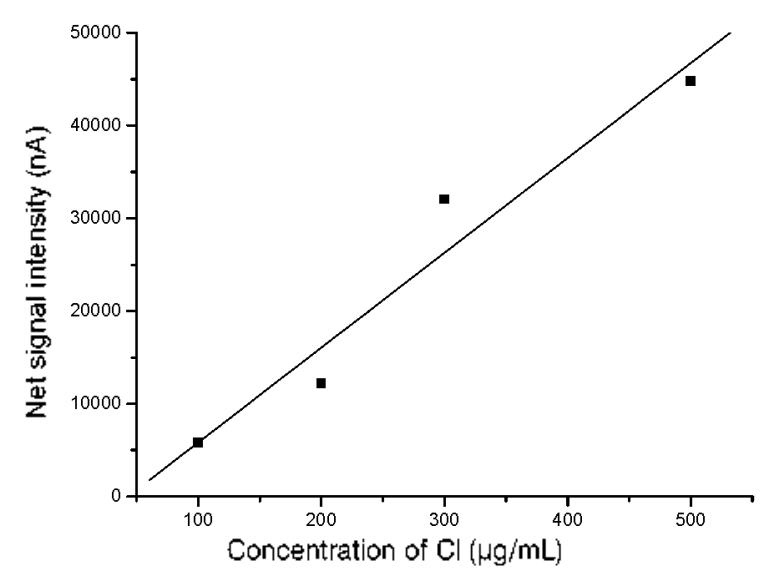

Figure 7. Calibration curve for $\mathrm{Cl}(\mathrm{I})$ at $837.71 \mathrm{~m}$.

For the purposes of this study. sanitizing solution was obtained from Duck Young Engineering (Gwachun. Korea), which has developed a prototype electrolysis system for the production of chlorinated water for sanitation purposes in the food and related industries. Chlorinated water was produced by electrolyzing $\mathrm{NaCl}$, and naturally hy'drogen gas is produced as a by-product. Sanitizing solutions can contain several types of inorganic chlorine containing compounds. such as chloride. ClO and several others. and although sanitization efficiencies were initially expected to be influenced predominantly by compounds like $\mathrm{ClO}$. total chlorine content determinations do in fact provide valuable information related to efficiency. The concentration of total chlorine in sample solutions during the present study were $\sim 4,570 \mu \mathrm{g} / \mathrm{mL}$ and the relative standard deviation of the analysis was $1.40 \%$ when the He-PMP emission system was operated under the optimized conditions.

Acknowledgments. This work was supported by Internal Research Fund of Dankook University (2008)

\section{References}

1. Bumett, A. B.: Iturriaga, M. H.; Escartin, E. F. J. of Food Protection 2004, 67, 742

2. Kwon, J.-Y.; Kim, B.-S.; Kim, G.-H. Korean J of Food Science and Techolog, 2006, 38.28 .

3. Beuchat, L. R. J. of Food Protection 1999, 62, 845

4. Nakahara, T. Nishida, T. Spectrochintica Acta, Pan B 1998, 53 , 1209 .

5. Pohl, P.: Zapata, I. I.: Amberger, M. A. Spectrochimica Acta. Part $B$ 2008, 63, 415 .

6. Tagami, K.; Uchida, S.; Hirai, I. Anolvtica Chimica Acta 2006, 570,88

7. Bass, A.; Chevalier, C.; Blades, M. W. I. Anat At. Spectront. 2001, 16, 919.

8. Raluman, M. M.; Blade, M. W. Spectrochimica icta Part B $1997,52,1983$

9. Sung, Y. I.; Lim, H. B. J. Anat. At. Spectrom. 2003, 18, 897.

10. Bilgic, A. M.: Voges, E.: Engel, U.: Broekaert, I. A. C. J. Anal. At. Spectront $\mathbf{2 0 0 0}, 15,579$.

11. Bilgic, A. M:- Engel, U.; Voges, E: Uchelheim, M. K.; Broekaert, J. A. C. Plasma Sonces Sci. Technol. 2000, 9.1.

12. Iza, F.; Hopwood, J. Plasma Soltres Sci. Technol. 2002, 1 , 229.

13. Minayeva, O. B.; Hopwood, J. A. J. Anal. At. Spectrom. 2002. $17,1103$.

14. Lim, H. B.; Kim, D; Jung, T: Houk, R. S:; Kim, Y. Analytica Chimica teta 2005, 515, 119 .

15. Houk, R. S.; Zhai, Y. Spectrochintica Acta, Pan B 2001, 56 , 1055

16. Abdallah. M. H.: Mermet, J. M. Spectrochimica Acta, Pan B $1982,37,391$.

17. Ishii, I.; Montaser, A. Spectrochintica Acta, Pan B 1991, 5986 1197.

18. Sung, Y.-I.; Lim, H. B.; Houk, R. S. J. Anth. At. Spectront 2002. 17,565 .

19. Mermet. I. M. Spectroscopic Diagnostics: Basic Concept in Inductively Coupled Plasma Emission Spectroscopv, Boumans, P. W. T. M., Ed.; John Wiley \& Sons Inc.: NY., 1987; Part 2, Chapter 10, pp 368-372.

20. Miro, M.; Estela, J. M.; Cerda, V. Talanta 2004, 63, 201.

21. Oh, J. Lim. H. B. Spectrochinica Acta Part B 2008, 63, 1263.

22. Ryu, W. K.: Kim, D. H.; Lim, H. B.: Houk, R. S. Bull Korean Chem. Soc. 2007, 28, 553 .

23. NIST website: http physics.nist.gow PhvsRefData Handbook: 